\title{
Increasing the share of RES in Polish district heating systems using power-to-heat technology
}

\author{
Matgorzata Kwestarz ${ }^{1}$, and Maciej Chaczykowski ${ }^{1, *}$ \\ ${ }^{1}$ Warsaw University of Technology, ul. Nowowiejska 20, 00-653 Warszawa, Poland
}

\begin{abstract}
The power systems in European Union operate under energy policies where the greenhouse gases reduction, the increase of the share of renewable energy sources (RES) and the improvements in energy efficiency are the main objectives. Polish energy sector is currently based on inefficient usage of coal and must be transformed according to the requirements of EU energy and climate policy. A policy framework for climate and energy in the period from 2020 to 2030 established the target of $27 \%$ of share of RES in energy consumption. With the continuing increase in the use of RES, it is likely that more and more generation will have to be curtailed to maintain the stability of the power system which was not originally designed to integrate renewable generation. In this context, the conversion of renewable electricity to heat in connection with its storage in district heating systems, known as Power-to-Heat $(\mathrm{PtH})$ can be considered as a viable option in increasing the share of RES and facilitating the stability of the power system. In this paper an attempt is made to estimate the potential of PtH technology for Poland up to 2030, including the high RES share scenario for the energy mix development.
\end{abstract}

\section{Introduction}

Much research is being carried out related to distributed energy sources and decentralized energy systems utilizing renewable energy sources (RES), including their integration to utility grids. Examples of research projects carried out in this field in Poland are given in paper [1] with the focus on the development of smart grids. Smart grids enable easier integration of distributed sources into the national grid, reduce the grid load by introducing the demand response programs and minimize the risk of blackout. The term smart grid focuses primarily on electricity sector and electricity infrastructure, while the concept of a smart energy system suggests a more integrated approach by coupling of the energy sectors and a greater range of energy infrastructure, i.e. natural gas, district heating and cooling, and transport infrastructure. Smart energy system can be considered as a system whereby the operations of smart electric, thermal and gas grids, combined with storage technologies are coordinated to identify synergies between them and in order to find optimal solutions globally for the whole energy system rather than locally for each

\footnotetext{
${ }^{*}$ Corresponding author: maciej.chaczykowski@pw.edu.pl
} 
individual sector [2]. Such a holistic systems approach as opposed to a single sector approach allows for the identification of more energy-efficient and cost-effective solutions in the field of energy conversion and storage. These include technologies such as power-to-gas (also $\mathrm{PtG}$ ) and power-to-heat $(\mathrm{PtH})$, which can develop into more achievable and affordable solutions to the transformation of today's systems into future renewable and sustainable energy systems. The term power-to-gas refers to the process whereby electrical power is used to produce hydrogen $\left(\mathrm{H}_{2}\right)$ or synthetic natural gas $(\mathrm{SNG})$ which can be injected and stored in the gas grid for later use in CHP plants, whereas power-to-heat $(\mathrm{PtH})$ assumes the conversion of electrical energy into heat using either resistance boilers, electrode boilers or heat pumps. The heat can be stored in thermal energy storage (TES) tanks or fed into district heating networks. The electricity used for PtH should be derived from renewable sources which would otherwise be curtailed due to system or line constraints.

Energy and heat generation is responsible for the largest share of $\mathrm{CO}_{2}$ emissions worldwide (approximately 42\%). If coal and petroleum products continue to be used intensely, climate protection targets for 2050 will not be met. However, implementing the global climate protection measures, which, according to DVGW (The German Technical and Scientific Association for Gas and Water) should consist of the Fuel Switch, Content Switch and Modal Switch (Figure 1), should enable COP21 targets to be met [3].

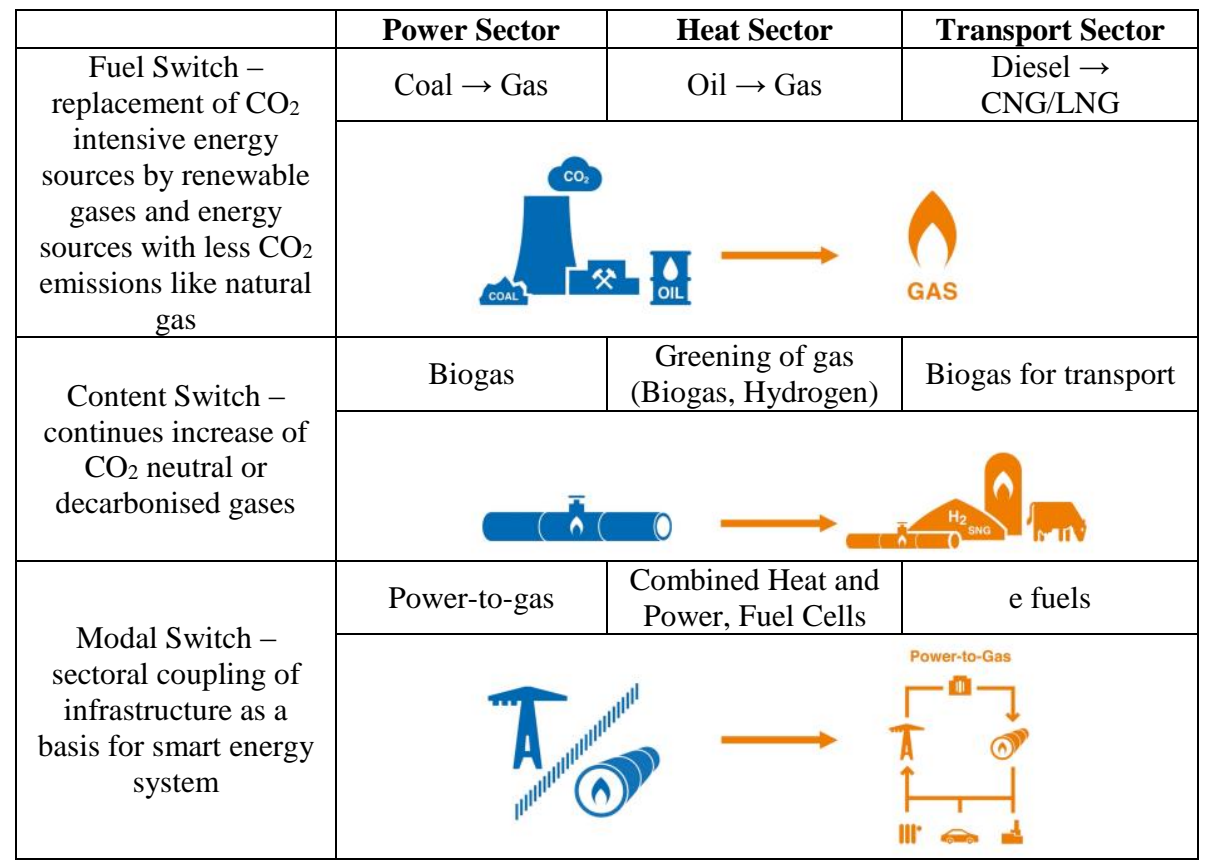

Fig. 1. Fuel, Content and Modal Switch in all relevant sectors as an example of climate protection measures (source DVGW).

Polish energy sector is currently based on inefficient usage of coal and must be transformed according to the requirements of EU energy and climate policy. While coupling between the power sector and gas sector with the use of PtG technology was amongst the subjects researched in Polish literature [4, 5], the subject matter of integration of the power sector with heat sector based on the PtH technology has received very limited attention so far. In this work we follow the methodology to investigate the impact of $\mathrm{PtH}$ technologies on electric and thermal grids described in [6] and [7] to examine the gross 
effect of the potential implementation of $\mathrm{PtH}$ on the district heating sector in Poland in the perspective of 2030 .

\section{Technical potential on the supply side}

Fig. 2 shows the domestic power demand in 2017 published by Polish Transmission System Operator (TSO) PSE S.A. Regarding the weekly dynamic, electric consumption drops regularly at weekends. There is also a visible drop in demand for electricity during holiday periods, e.g. the global minimum at April the $16^{\text {th }}$ and the local minimum at December the $25^{\text {th }}$. More detailed data on electric consumption for the $52^{\text {nd }}$ week of the year containing the local minimum in December occurring at a time corresponding to the Christmas season are shown in Fig. 3. It can be clearly seen that demand begins to fall and drops off for the period of 25-26 December 2017, primarily due to low consumption in the commercial and industrial sector. At the same time the TSO was confronted with a surge in electricity production from wind turbines, which enforced the centrally-dispatched generating units (CDGU) shut-downs and restarts in a daily cycle.

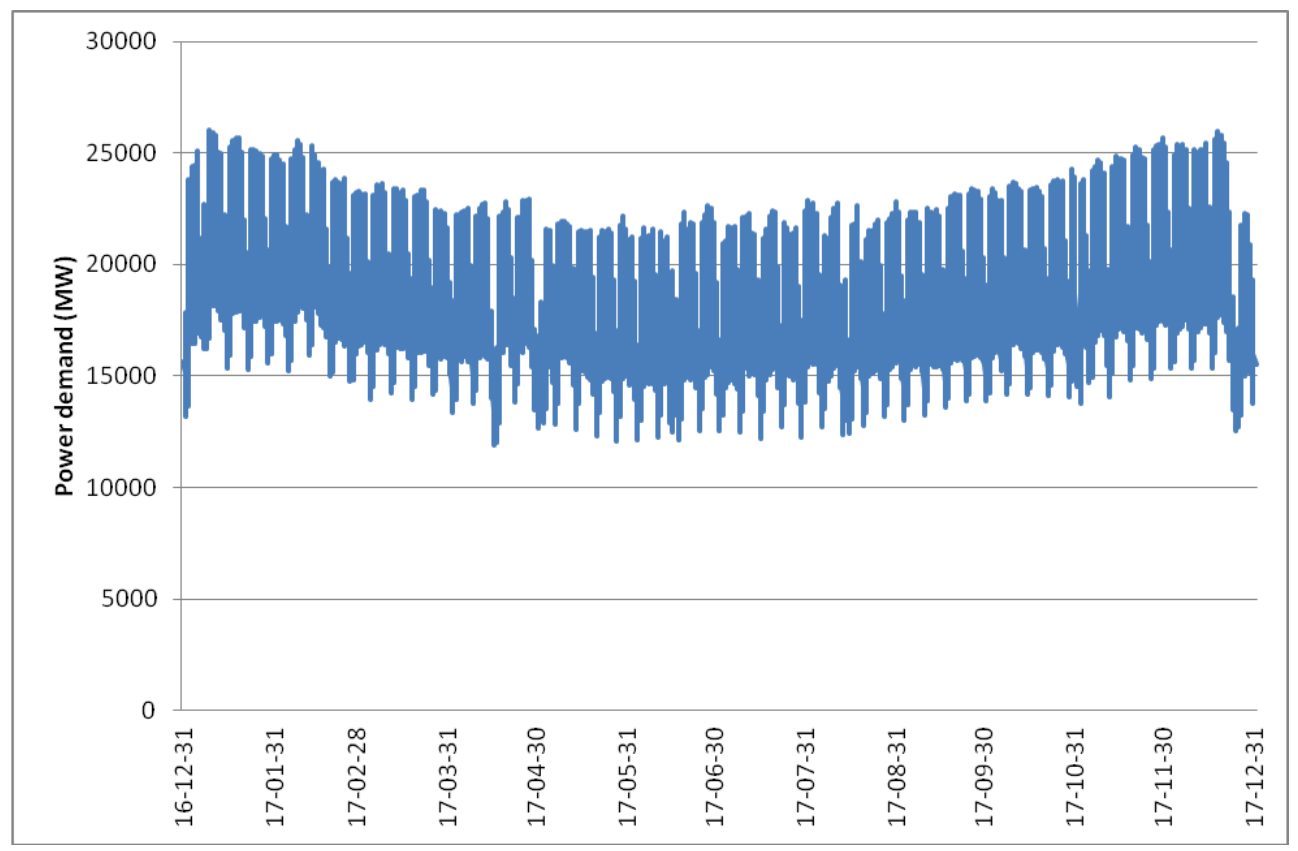

Fig. 2. Domestic power demand in 2017 (PSE S.A.). 


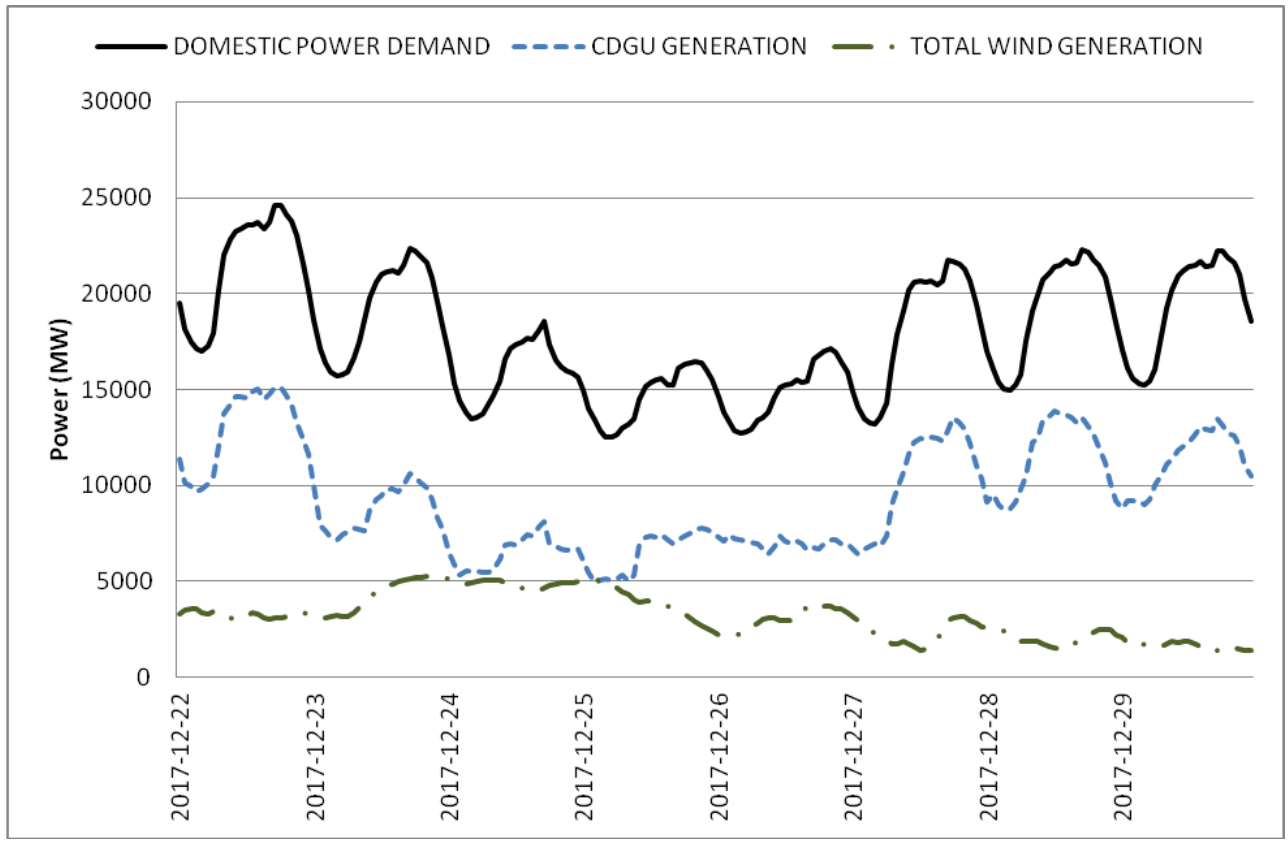

Fig. 3. Weekly dynamic in power demand and electricity generation in December 2017, CDGU - Centrally Dispatched Generating Units.

The number of the daily shut-downs of CDGUs is increasing as they are needed to provide the regulatory downward at the off-peak periods. It should be noted that CDGUs were not designed for intervention shut-downs which cause their premature wear and tear and increase their failure rate. Furthermore, it generates additional system operating costs of CDGUs restarting at the peak periods and working with their technical minimum outputs. As of 2017, the above situation corresponds with the share of RES in electricity and gross final energy consumption of $14.60 \%$ and $10.97 \%$, respectively.

While the European Commission policy framework for climate and energy in the period from 2020 to 2030 established the target of $27 \%$ of share of RES in total energy consumption, only the high RES share scenario of the Polish Energy Policy 2050 (PEP 2050) assumes the above figures transformed to the requirement for RES share in electricity consumption. In the remaining scenarios, including the reference scenario, the RES requirement is kept at $19 \%$ of the total electricity generation [8]. Recently published draft of Energy Policy of Poland 2040 (EPP 2040) assumes the above indicator at 21\% RES in gross final energy consumption in 2030. It needs to be stressed that in the strategic direction regarding the development of heating and cogeneration the technical development of district heating is related, among others, to increased use of renewable energy and promotion of heat storage and smart grids. The expected growth of RES share in heating and cooling sector in the above document is $1-1.3 \% \mathrm{y} / \mathrm{y}$.

\section{Technical potential on the demand side}

The analysis was carried out with the following assumptions regarding the potential on the demand side in Polish conditions. The prediction of the increase in heat demand from the customers connected to the district heating network in 2030 was based on the assumption that the current connection obligation will be extended to all centralized district heating 
systems for all buildings as proposed in EPP 2040 draft. The input data from Energy Regulatory Office report on District heating sector in 2016 was adopted. The hourly forecast was made with the following assumptions: $20 \%$ of heat ordered by customers is used for tap water production, which is consumed with the daily load profile, taking into account the differences between working days and weekends, while the remaining $80 \%$ of heat is used for space heating. The hourly load profile for heating was calculated as a function of dry-bulb temperature determined on the basis of typical meteorological years and statistical climate data for energy calculation of buildings.

Data regarding the domestic power demand and the variability of wind energy on the hourly and daily timescales were obtained from daily reports of the transmission system operator PSE S.A. from 2017. It has been assumed that annual electricity production in 2030 amounts to about $180 \mathrm{TWh}$, coal keeps its share in the power mix at $60 \%$, RES at $27 \%$, and natural gas at the remaining $13 \%$. It has been furthermore assumed that the transmission system operates with CDGUs at their technical minimum to maintain system security and reliability and at no electricity curtailed from coal and gas fired non-CDGUs.

Fig. 4 shows duration curve of the imbalance between power demand and the total production from RES and generation units including CDGU technical minimum due to the system's operational safety for 2030. Negative power values indicate the surplus of electricity in the system, therefore the power available for $\mathrm{PtH}$ plants is proportional to the area between the curve and the x-axis for hours with a negative power value. The number of hours in which electricity could be converted into heat under high RES share scenario in 2030 is 1364. The results of the calculations of energy storage capabilities using $\mathrm{PtH}$ technology are shown in Figure 5.

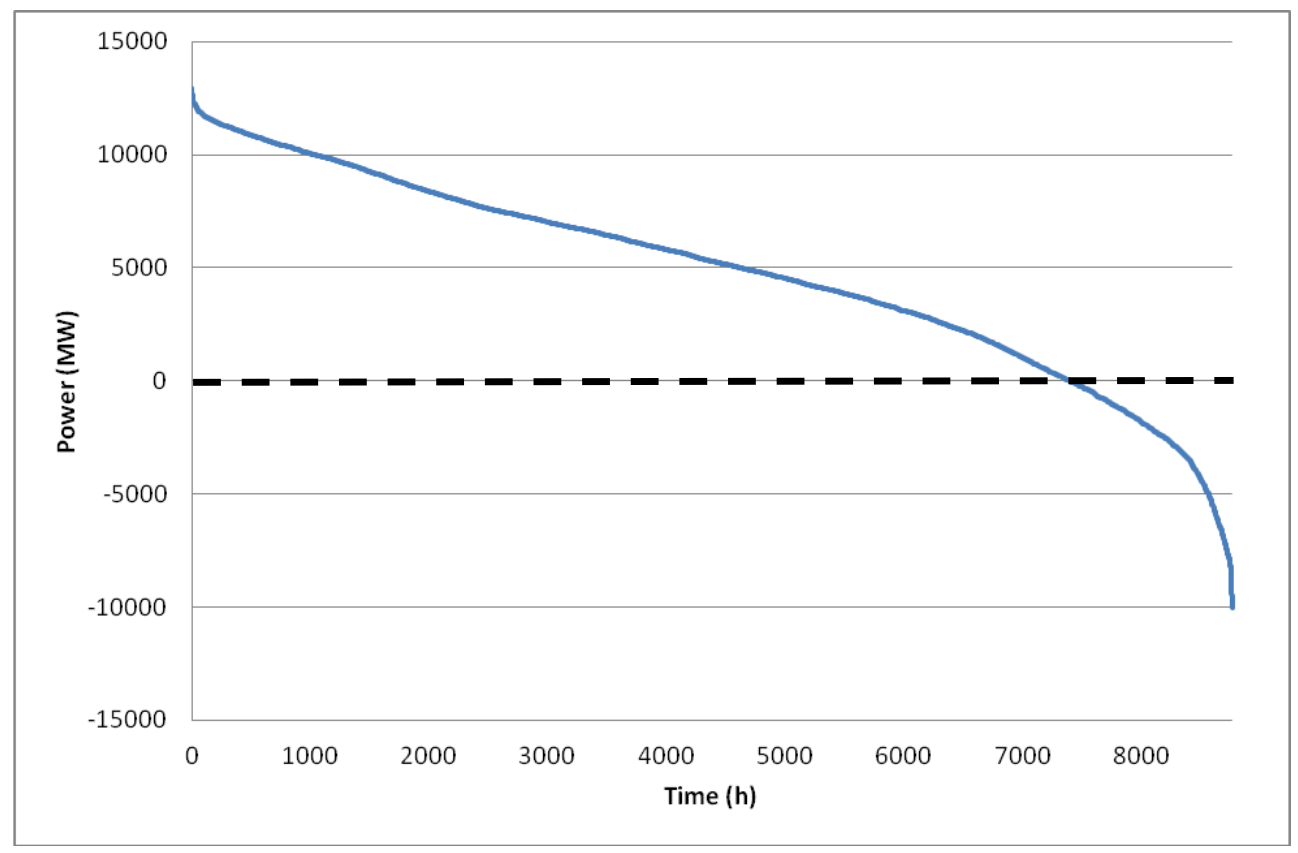

Fig. 4. Residual load duration curve under high RES share scenario for Poland in 2030. 


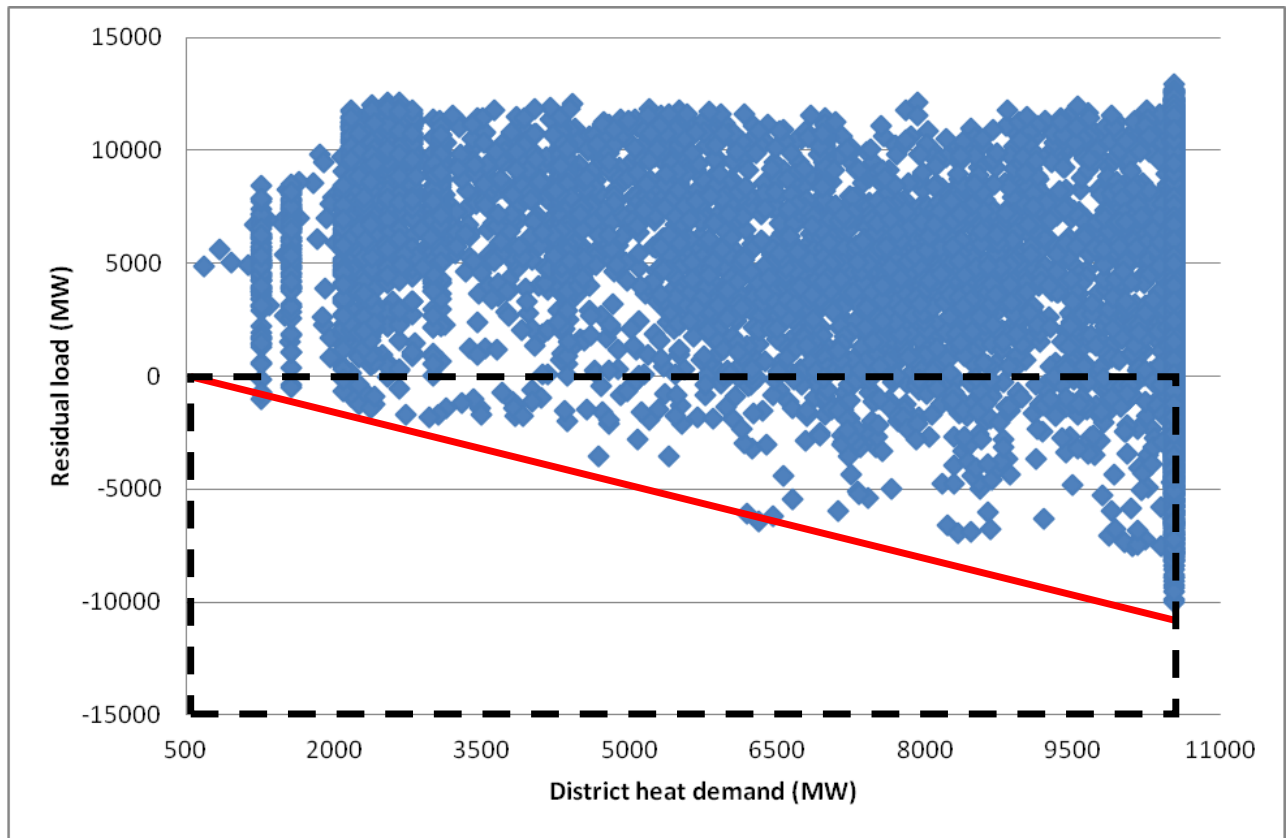

Fig. 5. Potential of PtH technology for Poland in 2030. Each blue point represents one hour of the year 2030 with the corresponding district heat demand and the residual load. Red diagonal line represents hours in which the heat demand equals the negative residual load.

Fig. 5 shows the hourly district heat demand plotted against the corresponding residual load for the high RES share scenario in Poland. The hours of the year in which negative residual load and heat demand occur simultaneously are located inside the black rectangle. The triangle above the red diagonal line frames the data for hours when all of the negative residual load can be can be absorbed by district heating load. There are hardly any periods represented by points below the diagonal line in which the negative residual load exceeds the district heat demand, which means that the potential of power-to-heat is almost unrestricted by the heat load. In these hours the excessive heat production of $\mathrm{PtH}$ facilities must be stored in TES tanks. The results of the analysis showed the potential of $\mathrm{PtH}$ technology in Poland in 2030 at the maximum level of $10 \mathrm{GW}$, which corresponds to 3.56 TWh of stored heat, in the period of 1364 hours.

\section{Conclusions}

With the intermittent electricity generation in RES, optimal production allocation, adequate storage capacity as well as the flexibility of energy storage will play a pivotal role in the management of power systems. The electricity used for $\mathrm{PtH}$ could be derived from renewable sources which would otherwise be curtailed due to system or line constraints. The heat could then be stored in distributed thermal energy storage units and fed into lowtemperature district heating grid as a low-carbon heat.

The presented analysis confirms that heating systems in Poland provide adequate conditions for converting large amounts of electricity from renewable sources into heat. The assessment of the $\mathrm{PtH}$ technology potential concerned only technical aspects and provided no answer as to the scope of possible application. Considering the large gradient of the function presented in Fig. 4 in the negative value range, a sensitivity analysis of the $\mathrm{PtH}$ potential to changes in maximum power/annual working hours needs to be carried out. 
For example, by reducing the maximum power range of $\mathrm{PtH}$ installations to $5.5 \mathrm{GW}$, we receive the annual working time of the installations only seven days shorter, with the heat production at 2.4 TWh. The relation between electricity prices and fuel costs, including taxes and carbon pricing, will be a decisive factor for business models.

\section{References}

1. J. Kiciński, Transactions IFFM 127, 7-25 (2015)

2. H. Lund, P. A. Østergaard, D. Connolly, B. V. Mathiesen, Energy 137, 556-565 (2017)

3. https://www.dvgw.de/medien/dvgw/leistungen/publikationen/staying-within-theglobal-carbon-budget-dvgw-brochure.pdf

4. M. Chaczykowski, A.J. Osiadacz, Transactions IFFM 137, 85-103 (2017)

5. M. Chaczykowski, Ł. Kotyński, M. Kwestarz, P. Zarodkiewicz, Przemysł Chemiczny 98, 2 (2019)

6. D. Böttger, M. Götz, N. Lehr, H. Kondziella, T. Bruckner, Energy Procedia 46, 46-253 (2014)

7. G. Schweiger, J. Rantzer, K. Ericsson, P. Lauenburg, Energy 137, 661-669 (2017)

8. M. Wierzbowski, I. Filipiak, W. Lyzwa, Renewable and Sustainable Energy Reviews 74, 51-70 (2017) 